\title{
Discussion on Media Report on Group Events
}

\author{
Fanbin Zeng \\ College of Journalism and Communication, Jinan University \\ Guangzhou 510632, China \\ E-mail: zengfanbin@vip.sina.com
}

Received: August 8, $2011 \quad$ Accepted: September 27, $2011 \quad$ Published: January 1, 2012
doi:10.5539/ach.v4n1p54
URL: http://dx.doi.org/10.5539/ach.v4n1p54

This research thanks for the support by Panmedia Institute ("PMI", http://panmediainstitute.com/) with the items number 20114-008.

\begin{abstract}
Group events that occurred in China show a trend of increasing in the number, rising in the scale and range extension. With environment and society changing, the media have reported the group events these years. However, facing to the challenge of mobile phones and the Internet and other new media, the final reported results of the media are not satisfied. This paper points out that there are some questions about the media such as the slow reflection of the earlier reports, abrupt end of the later reports; being lack of objective, fair quality, or even false information and so on. It also analyzes the constraint factors from three aspects of the rise of group events, the risk of group events, the game between the government, the media and the public, as well as the legal system.. This paper points out that the emergence of group events presently in China has profound social reasons, which has not only a negative function, but also has positive features. The media need to act as a "social safety valve". Correspondingly China needs to expand the coverage of group events in the media and to increase the amount and degree of the media reports of social issues and social contradictions.
\end{abstract}

Keywords: Group events, Media report, Safety valve, Social conflict

\section{Introduction}

Within the transformation from planned economy to market economy, the emergence of group events throughout China shows a tendency of increase both in quantities, scale and range. As for the increased quantity, according to the report from "outlook weekly" in September, 2008, the relevant statistics show that in 2006, the group events exceed 90000 all over the year, while in 1993, the number is much smaller as 8700 , and 87000 in 2005 , which indicates a continuous increase in the group events in quantity during recent years. (Xinwen Wei and Feng Gao, 2008) As for the scale, it is quite common that hundreds of people have been involved in, while there are also several events that have involved thousands of or even more people in. Furthermore, some events have even involved in people from different units and districts, or a pretty large number of participants. As for the range, the group events happened in recent years scatter all over the corners of the country, relating to various industries such as construction and transportation. The diversity of the participants is obvious as people of all ranks and classes, such as staff both employed and out of work, farmers, migrant workers, sole proprietors, demobilized servicemen, and even students can be found in the events.

\section{Theoretical framework and literature}

The "Group events", referring to a kind of collective motions, is a political term with Chinese characteristics. In the documents "Consensus about prevention and proper handling of group events" formulated by General Office of the CPC Central Committee, "group events" is defined as "mass movements caused by the contradictions among the people, who think their rights have been infringed and try to express their wishes and requirements through ways like illegal gathering or containment. Including those illegal concatenations and gathering in the process of the campaigns coming into being" (Xinwen Wei and Feng Gao, 2007). The main principle in the traditional solutions of group events are to try first to make the events sound less serious and then to reduce it to 
nothing at all. The mainly adopted method is to cut the events off from the outside world. That usually concerns blocking the passage of the information about the events, in which the media's intervention is not allowed, so that the government can act as a role of third party in the benefits coordination of both sides. Comparing the difference between China and western country in institution background, researcher Liu Neng pointed out that "generally Chinese media is prohibited to report group events no matter they are routine or not, or they happened in urban or rural districts". The media's not reporting makes the dissemination of the occurrences and more related information of the group events confined to the local range. As a result, such group events can not develop into national events, thereby reducing the possible intervention of the significant third party (Neng Liu, 2004).

However, such a transmission control cannot achieve the goal of effective management of the group events. With the changes of the natural environment and society, the media has begun to report the events in recent years, while the outcome is so satisfying due to the challenge from mobiles and the internet on information transmission. For the media often distribute rumors or wrong information. What is the crux and how can we find proper solutions to the dilemma of the media's report about the group events? This paper will mainly focus on the analyses on how to understand the problems and constraints of the media's report, in what way we may regard the group events in China, and how the media should behave to accomplish its social function.

\section{Methodology}

In what way the media report the early and later stage of the events, as well as how the media define the nature of the events? In order to explore this problem. The media report we are analyzing here refers to the mainland media's report on the four group events listed below. Considering the government websites can hold the post of media function when issuing the information of the group events. In addition, the authorized issuing tends to be reprinted by other media. Therefore, here we take the information from the government website as media report. here we have chosen the event happened in Dingzhou City, Heibei Province in 2005; On June 11, 2005 4:30 am, in an open land outside the Shengyou village in the south of Dingzhou City, Hebei Province, 200-300 young men wearing the safety helmet and camouflage uniforms attacked the villagers living in the shanties. The attackers were all armed with shotguns, bush-hooks, cudgels or fire extinguisher .The attack has gotten 2 people killed on the spot, left 4 deaths in hospital and 51 villagers badly injured. The attack has been part of the conflict between the party of land requisition and farmers who have rejected the low price. The attack was supported by local relevant department. The events happened in Weng'an City, Guizhou Province in 2008, On June 28, 2008 in Weng'an, a small town in the north of Guizhou Province, the bizarre death of a girl of junior high led to a mass violence event beleaguering the government buildings. The impulsive mob has ransacked the bureau of public security, the government of the county, the local bureau of finance, and the office building of the county committee. Several policemen have been wounded. The office building of the Weng'an County Committee as well as the 104 offices in the county government has been burnt down. In addition, 150 people have been injured in the incident. the event happened in Menglian City, Yunnan Province in 2008, On July 19, 2008 in Menglian County, Yunnan Province, when trying to arrest five farmers who grew rubber in Mengma town, as part of the action to improve the public security of the rural area, the police suffered from the siege of five hundred farmers armed with cane knives, iron rods or spades. 41 police have been hurt and 9 police cars have been damaged. The police used baton guns for self-defense. The incident also left 2 deaths and 15 injured among the farmers when the event happened in Shishou City, Hubei Province as a sample. During June 17 and 20, 2009 in Shishou City, Heibei Province, the abnormal death of a hotel chef lead to the mass incident in which roadblocks were set up to block the traffic. On June 25, 2009, the government of the city announced that the chef's death, as a result of falling down from a building, was a suicide. On July 25, 2009, the municipal committee of Shishou city convened a conference of leading cadres to announce the appointment and removal of the party secretary of Shishou City, as well as other officers. Ming Zhong, the party secretary of Shishou City was deposed for the mishandling of the incident. These four events have had very serious social impact, and have raised great attention from the news and broadcasting industry. The analyses focusing on the media report consist of the report of the events on early stage, the report of the later development of the events, and the quality of the report.

The early report refers to the very first report of the events and its related information, which can be divided into reports concerning the latency period, the fermentation period and the very first stage of the events. The latency period refer to the time just before the occurrence of the event, which is directly related to the occurrence, or related to the upsurge of the public sentiment. The fermentation period refers to the time from the guiding to the occurrence of the event. The very first media report refers to the formal and authorized report of the event just after its outbreak. According to the division, here the reports of three different periods of the four events mentioned above can be listed in the following table1 which shows that media reported slowly in early group 
incidents, few focus are placed on the deep-seated problems and contradictions behind group incidents.

3.1 Later reports to events refer to the reports carried out by all media after the earliest direct issue. The following analysis of Dingzhou and Weng'an events

After the media public report to Dingzhou event, The research of attach to villagers in Dingzhou, Hebei, which was the most detailed report, was published by China Economic Times on June 20, 2005. The whole event of attach to villagers on June 11 in Dingzhou, Hebei was published by Life Week on June 23, 2005, and had a deep-seated analysis. And some news reviews were also published by Nanfang Daily, Beijing Youth Daily and Easyday.

However, from June 18 to late December, 2005, the state news agency Xinhua news agency on its website XinhuaNet were released so far only four related news reports and a news reviews, and the first news report had only 61 words:

a) News reports

XinhuaNet: Result from land disputes, a contractors in Dingzhou, Hebei have organized some hatchet men to siege the villagers, resulting in six deaths and dozens injured; currently the 22 suspects including the organizers have been arrested. XinhuaNet 2005-06-18 16:37

The attach to Dingzhou villagers has made important progress, the communist party secretary has been arrested. Xinhua Net 2005-07-11 09:00

Dingzhou, Hebei: Shengyou Village no longer has land requisition; villagers said support XinhuaNet 2005-07-21 01:43

The case of June 11 attach to villagers in Dingzhou is in session, 27 people including the previous secretary are sued. XinhuaNet 2005-12-16 09:06

b) News review

Look into "good governance" by the arrest of two levels secretary in Dingzhou event XinhuaNet 2005-07-15 09:17

After the Weng'an event had been reported in public, media in Guizhou province were allowed to reported the Weng'an event from June 30, 2008. On June 30 and July 1, the big newspapers of Guizhou province all used the unified caliber to report the news, like Properly in accordance with 6.28 emergency, Shi Zongyuan commanded in Weng'an, emphasized the good remedial works to do after 6.28 emgergency and good handle the relationship between maintain stability and economic development, but they don't talk anyting about the case of Li Shufen. Meanwhile, the government also limited and disturbed the media outside Guizhou province report, weakened the guiding consensus function of media in emergencies(Yong Chan, Jian Wang,2009) Later the meeting of Guizhou Daily required more implementing the fact itself according to the new requirements from the secretary Shi Zongyuan. And then Guizhou Daily adjusted the direction of reports, published several articles about the case itself, and also reported the case of Li Shufen, but time has appears delayed, and causes the veracity doubt from Internet users.

Above, although media are very concerned about mass incident, the reports always come to an abrupt end, difficult to go further, and lessen along with the events.

\subsection{Report quality of events refers to the degree of reality, objective and justice}

In the reality aspects, faced various ways spreading the mass incident reports, media reports (including government website) incredibly appear obvious fake news, as in the streets already built barricades in Shishou, the released news was as following.

The bus fire accidents disposal exercise jointly organized by many departments held

Jun 20th, 2009 15:35 Source: Cnhuibei Net

June 19 9:00 am, Hubei Shishou trucks company, united fire department, traffic police, medical department,

held a bus fire accidents disposal exercise, the municipal government leaders visited the exercise.

(Correspondent: WangFang)

The more what the government tries to hide the more it exposed, this kind of reports can cause more rumors spread and the credibility weakened.

In the objective, justice aspect, the media is often difficult to balance the interests of both parties in the mass incident, and only focus the voice expression of public power. 
An emergency happened in Weng'an, Guizhou

2008-06-29 05:49:38 Source: XinhuaNet

June 29, Weng'an, Guizhou, XinhuaNet reported: An battered government emergency happened in

Weng'an, Guizhou, on June 28 afternoon.

According to the introduction of local police, on June 28 afternoon, some people gathered to the

government and public security bureau because of the dissatisfact with a female student death appraisal

result from the public security bureau. In the government officials reception process, some people inciting

the unaware of the truth crowd impact the public security bureau, government and the county building.

Then, a few outlaws disturbed and fire many offices and some vehicles.

After the incident, Guizhou provincial party committee and the government immediately urged for the proper disposal as soon as possible. Guizhou Provincial Committee and secretary of Politics and Law Committee, the head of Public Security CUI Yadong quickly reached to the scene and guided the local

Party committees and governments dispose and quell the incident. At 2 am, 29, onlookers slowly dispersed, and the situation did not further expand. The circumstance of Weng'an County had returned to normal.

(Article Source: Xinhua)

In the news, "traditional" language and perspectives are used-focusing in the fight against lawless persons, but report on the facts of the case itself is not much. It just very briefly describes some people attack and impact the government. There were no explanations on the death of the girl student, which was the blasting fuse of this incident. The news just concluded the incident with only one sentence "Some people dissatisfied with the death appraisal of the girl student by the Public Security Bureau of Weng'an County", and indicated that the incident was basically solved. In addition, no participants in this group incident were specifically interviewed.

Another example Menglian incident, according to the press conference of Pu'er city government on July 23, 2008 , it was said that "Under the instigation of a few people with ulterior motives, more than 500 people, who were unaware of the truth, became agitated and behavior ultra. They struck the warning line and attacked the police with long knife, steel, iron rods and sticks, which made several policemen were injured". in the news "An Abnormal Death Occurred In Our City" released on the Shishou City government website on June 19, 2009, it is also mentioned that "Many people unknowing the truth rockblocked, obstructed the traffic and booed on the Dongyueshan road and the East avenue in the city on the $19^{\text {th }}$ ". These news did not make any specific analysis for the people defined them as "unknowing the truth", or "under instigate by very few people with ulterior motives", or "obstructed the traffic and booed". Its essence is to use media discourse to sentence without trial.

\section{Results}

Group incidents reported restriction factor analysis would be found out in the following. The events are the major form of China's social security events. Social security and industrial accidents, public health, natural disasters constitute four types of public emergencies at present. For the last three categories of public emergency, a lot of progress has been made by the media. Industrial accidents as reported, Permeable production accidents occurred in Nandan, Guangxi Province on July 17th 2001, killing 81 workers. After the incident, Guangxi press uncovered the truth through a joint with foreign media and breaking the limit. Nandan accident is the first case of major industrial accidents first revealed by the journalist. Since then, there is no limit to publicly report the industrial accidents by the media in China.

In reports of public health, when SARS occurred in 2003, the media basically in a state of aphasia before the end of March--they initially was ordered not to report, then "played down". April 1 to 20 is the period of partly reporting. The situation has been expanded, sweeping public opinion abroad, but domestic media remained silent on the serious condition, only reported with understatement. April 21, the central health minister and Beijing were announced recall by the central government. After that the country began to report the situation more fully, and the epidemic was reported everyday to carry out an objective, comprehensive, timely, factual reports (Jintao $\mathrm{Hu}, 2008$ ). From never reported to fully reported, China's media have made breakthrough over the all sorts of restrictions and constraints formed in the past few decades and lay the foundation for the overall report of the public health events.

In the aspect of natural disasters, China's media gave the extremely rapid response and fully reported the Wenchuan earthquake in 2008, which was praised by General Secretary Hu Jintao. He said: "In the struggle of 
the earthquake relief work, we timely report the earthquake situation and the disaster relief situation. We deeply disseminate the great spirit of earthquake relief work, which plays an important role for giving confidence to the cadres and the general and inspiring them to unite as one to do the earthquake relief work. We are spoken highly by the cadres and the general and gain the good reputation of the international society. The successful experience is worth summarizing carefully. Also, it ought to form a institution for long-term adherence". From what can be seen, our media's reports on public emergencies are technically remarkable. However, why is it difficult for media to make a difference on the group incidents? I believe that group incidents reports are mainly enslaved to the following factors:

Group events are more risky than other events. Group Events, and other public emergencies occurring frequently, reveal that our country has to face a complex "risk society". "Risky society" concept is put forward by a famous German sociologist Ulrich Beck in his book Risky Society in 1986. He believes that "In the modernization process, the exponential growth of productivity, would release the risk and potential threats to a level that is hitherto unknown". (Ulrich Beck, 2004) The group incidents are more risky than the other public events like industrial accidents, public health events and the natural disasters. This is because: first, industrial accidents, public health incidents and natural disasters are mainly belonging to the natural risk, also known as "external risks". But the groups incidents, which are belong to the man-made risk, are directly related to the society and the masses. They are also called the "inherent risks". External risks could be dealt with by gathering the power of the masses, however, the inherent risks would cause split inside the group, making it difficult to form groups together. Thus dealing with the external risks is less difficult than the inherent risks. Secondly, sudden events like natural disasters, industrial accidents or public health emergencies, generally would not fundamentally challenge the core of the whole system of society, mainstream values and the social structure. Not like the sudden events, group events is often squarely aimed at the core of the whole system of society, mainstream values and the social structure, challenging the legality and legitimacy of the existing order, so the threat is greater. Finally, the risk of the industrial accidents, public health emergencies, and natural disasters is regional and localized. But the group events can lead to social crisis of confidence and serious consequences of social disorder, resulting in the query of the masses on the bureaucracy and the state's legitimacy. It would be very easy to spread to other areas, other people and cause more serious consequences to the society if the control is bad. It is because of the insufficient understanding and grasp on the risk of the group incidents, the government and the media are restricted in the previous thinking mode of not reporting or less reporting.

The game between the government, the media and the public. In group events, the public's need of information is much greater than in normal circumstances. It requires more highly that the government and the media release the relevant information with accuracy, sufficiency and without delay. Originally, in such circumstances, the government needs to open government information and give service to the public. Moreover, the media not only become the most effective disseminator for the government information, but also request the government to disclose certain information.

However, after group incidents happened in some places, the local governments always cover up the truth and block the important information for solving the so-called regional "stability". Some officials are convinced that blocked may affect the critical information of the social stability, helping maintain the local stability. Such rhetoric was the main basis that some officials not timely open the relevant information. For example, it is explicitly stipulated about the news reports on the groups incidents by the Article 6 the 21st paragraph of the Prevention and Treatment Measures for Implementing the Masses Events, released by Jinzhou City, Shenzhen City in September 30, 2005 that:

In principle, group incidents in principle not publicly reported. As for several serious, especially serious group incidents, in order to correctly guide public opinion, if necessary, the on-site command can set up News Leading Group, which consists of the Municipal Party Committee Propaganda Department (City Information Office), City Emergency Command Center and other department. The job of the News Leading Group is to release information, arrange and coordinate press interviews, strictly audit published, broadcast-related articles, support and help the interviews of Xinhua News Agency, CCTV, provincial-level news media and so on.

Facing the group incidents, the media often encounter barriers of information opportunism because of the collusion between local government and business.

On the one hand, the media exists as a mouthpiece of the Party and government propaganda instruments, the Party's principles as their highest political principle, and the game process in the system carefully along the edge of the interests of the institutional framework to maximize the operation. On the other hand, the diversification transformation of social interests forces the media itself constantly to adjust their roles and social position to 
uphold the public interest as a new professional conduct and ethical standards, but the principles of system implementation also reflect very strong practical considerations. Especially in the face of mass incidents, the propaganda discipline provisions generally do not allow the media coverage itself, but by the relevant consent, issued by the Xinhua news release unification, can be reproduced in other media (Weiliang Wang, 2008). So the bottom line does not violate propaganda discipline becomes the reason of a media event in a group of aphasia.

Legal system is imperfect. After the Sixteenth Party National Congress, China's government in the production of accidents, public health, natural disasters have made great progress in terms of information disclosure, such as 2005 's "the notice of natural disasters on the total number of deaths and related information to decrypt" and 2006's "State of public emergencies overall emergency response plan" for the disclosure of these events provide some institutional support. However, the reported mass incidents, or vaguely related to the legal system, or lack of supporting legal protection, such as the 2007 introduction of the "Emergency Response Law of the People's Republic". Although the media to strengthen the autonomy of emergency information released, but the the relevant provisions of law, such as information dissemination, provision, and no more detailed explanation, which may cause some local governments drill legal loopholes, and engage in higher levels of government and central information blockade.

It is particularly worth mentioning is May 1, 2008 implementation of the "Republic of China on Open Government Information" (hereinafter referred to as "Regulations on Open Government Information") which provides that: "the administration should be timely and accurate disclosure of government information", "Administrative organs should take the initiative to open government information through the Official Gazette, government websites, press conferences and the press, radio, television and other means known to the public to facilitate public". But the "Open Government Information" under the State Council, "Regulations and administrative regulations to establish procedures" provides for the making of, the legal hierarchy are administrative rules and regulations, so, if the "Open Government Information" by the scope of government information disclosure requirements and is in its upper the "State Secrets Law", "Archives Act" inconsistent, then an invalid. The "State Secrets Law", the thrust of the legislation is to maintain the confidentiality of files held, "Archives Act" legislation should be to save the file, but they are the guiding ideology of the legislation as "not open to the principle", which is "government information disclosure regulations", the legislation is contrary to the concept. Thus, in the present legal system, "Open Government Information" may be negated by the higher law relegation idling. In fact, in the "Open Government Information" after the implementation of the face of public demands all kinds of information citizens, many problems were established. According to reports, "information does not exist", "An internal information", "affect social stability" as many government departments the most common reason to quibble information public (Yongtong Su, 2008). Imperfect legal system led to the reported mass incidents in China not actively or insufficiently.

In short, the above three constraints lead to reports of mass incidents in China lagging behind other emergent public events. To address these constraints, it is necessary to think the reasons of group events and functions of reflection, only in this way can we understand the problems of mass incidents and definite clearly what role should be in the mass media treatment of events.

\section{Conclusion and Discussion}

At present the cause and function of mass incidents in China.To understand the causes of the current mass and function, at first, we should analysis the current population types of event. Group events are main forms of social conflict. Social conflict theory was first originated in Marx, Weber and Simmel through the medium term, the most Hou Kese, Dahrendorf to conflict theory. Dahrendorf thought that the conflict is "obvious conflict between the competing social forces, competition, dispute and tension" (Li Zhu, 2006). Dahrendorf's definition is abstract, specifically, the conflict is a different individual or group action that two or more parties, the target is inconsistent, and against each other as a form of social interaction. Subject of conflicts is more complex, there are conflicts between individual and individual, conflicts between groups and populations, conflicts between individuals and groups, but social conflict in general is the larger power between groups confrontation.

Some researchers in accordance with domestic more than 60 groups incidents of data analysis found that the type of group conflict events are divided into direct conflict economic and social type of indirect conflicts (Li Zhu, 2009). Economic performance of a direct conflictis basically in the group events and interest groups to benefit the interests of impaired direct conflict between groups, also known as rights-based group events, such as the Dingzhou incident events fall into this category Menglian such incidents mainly derived from certain harm interests of the public. Type of indirect conflict society mainly in the security event for the fuse caused the sudden mass incidents, such incidents often lead to massive social unrest, also known as vent-type of group 
events, and the Weng'an incident Stone first event of this type. Vent-based conflict caused most of the original participants have no direct interest in the event, mainly Road see injustice or ulterior motive to vent their dissatisfaction with society.

Whether the conflict is a direct economic or social type of indirect conflict, it can reflect the deep-rooted in our society's problems, it can be said that the frequent occurrence of mass incidents is not accidental, but has profound social causes:

From the social structure, many scholars believe that the conflict should be attributed to China's social tensions in the social structure (Xueyi Lu, 2002). Lu Xueyi divided Chinese society into ten sectors and pointed out that the bottom of Chinese society has a large middle class, less features. Sun Liping's research indicates that: After Chinese society entered the nineties of twentieth century, compared with the eighties, the gradual transformation of social structure into a different direction, its essence is "breaking" "fracture" phenomenon in urban and rural, employed and unemployed middle-class and between the bottom of vulnerable groups (Liping Sun,2003). Li Qiang found an inverted structure of social strata in China, "Ding type", that is, the large number of lower, middle, upper uniform distribution, but the numbers are small social forms, this social structure is extremely rare, is a form of differentiation serious structural abnormalities. Li Qiang thinks that China has entered a "social structural strain" that is "the social structure of the lack of coordination, and makes the relationship between social groupsare in a confrontation, contradiction or conflict in the state or Social relations are a very strong tension. In such a state, the social contradictions intensify more easily, social problems and social crises more likely to occur". (Qiang Li, 2005) Imbalance in the social structure of different social classes lead to confrontation and conflict can not be resolved in the economic interests or have some kind of emergency situation caused by the outbreak of discontent, the extremely violent social confrontation, that is, the outbreak of mass incidents.

From the social system, our country is currently in a relatively closed system. Political leaders and government administrators have in a relatively closed system rather than an open election system, the interests of consultation mechanisms for expression and relatively occlusion, such as the function of representative bodies has not been played, civil society and autonomous organizations within the system did not Institutionalized channels of communication, news media and other channels of communication functions to some extent limited or subject to government restrictions, which are a direct result of lack of the necessary systems to effectively regulate the conflict between citizens and governments and conflict. The rule of law in China is not perfect, either government or citizens themselves, their behavior is often intentionally or unintentionally, to avoid legal means. This is a result, many citizens rights have been infringed, is not an option according to the appeal, choosing instead to more extreme mass incidents. In addition, some managers look at the issue of class struggle with the old thinking has not changed, no experience handling mass incidents, keen to eradicate the source of social unrest could trigger all kinds of causes and from head (such ascollective petitions and petition the tight control of leapfrog) (Weidong Zheng, 2009), So the expression of social interests and needs of the public security, it is difficult to carry through institutionalized channels, and ultimately make people choose to non-institutional channels and means to defend their own interests. In the event of dealing with certain groups of managers threatened the use or excessive use of legal violence, which intensified the conflict and intensified social conflict.

From the perspective of social equity, social injustice of transition caused a mass incident. China is in a transition period of rapid social change, a new mechanism for social justice has not yet established. Although the overall economic development, but there are a lot of social injustice. Some people and some regions get rich first to rely on honest work, but there are some people through a variety of improper means to obtain the social wealth and social inequality that serious, at this time, is the most prone to discontent. As the American sociologist Eric • Robert Horry said, "hardship does not automatically generate dissatisfaction, but dissatisfied with the degree of hardship does not necessarily proportional to the degree. Most rising discontent, when the degree is likely to be suffering when barely tolerable; living conditions have improved, resulting in an ideal state when seemingly within reach" (Gustave Le Bon, 2004) In the meantime, some local governments long-term administration does not act irresponsibly, causing disturbance of social order and even out of control, Lack of protection for the interests of vulnerable groups; justice unfair, unjust, long letters to no avail, the impression that inexcusable, mental depression; and moral system collapsed, people lost, the long-term accumulation of these deep-seated contradictions, lack of effective troubleshooting With ease, the case of emergencies, it is easy brewing into mass incidents.

After understanding the causes of group incidents, we need understand the social function of mass incidents. Conflict theory thinks that group harmony both within groups and consistency, there are contradictions and 
conflicts. Contradictions and conflicts between groups are both negative and destructive effects, under certain conditions, but also with enhanced adaptability groups to promote the positive integration functional groups.

Group Events has a dual nature, which is not only not conducive to social stability and social development of the negative features, but also promote social integration and social progress of the positive function, and its specific performance is as follows:

The negative features. Group events' negative functions of social conflict is obvious, group events for groups of social life, interests, social conflicts, in a certain time and place of gathering a range of joint implementation of the breach of social norms, disturb social order Behavior, social relations, the emergence of a lack of coordination, disharmony is the negative factors affecting social stability. Group Events is also a anti-social behavior, and highly destructive, and may lead to social unrest, the adverse consequences to lose morale. Group events while the characteristics of infection with each other, may make non-rational emotional impulse transmission in different populations, groups of more than serious incidents together, resulting in a strong shock to society, or even shake the regime's legitimacy. Legitimacy of any rule must face a problem, as Max Weber said "customs and interests, as the pure combination of motivation or emotional motives purely rational value, as a rule can not constitute a reliable basis (Rongyuan Lin, 1997). In addition to these factors, in general, but also add another factor, on the legitimacy of the faith". Thus, group events will be a direct result of the extreme expansion of the rule of crisis.

\subsection{Positive function}

Group events of social conflicts triggered by events not only have negative features, there are positive features. Lewis A. Coser conflict theorists believe that if the basic groups involved parties to the conflict, core values, then the conflict will result in the destruction of the social structure. If the concept does not involve the core values of society, then the conflict will play a positive social function of the structure (L.A.Coser, 1960). Some experts pointed out that the rights of the event type of group characteristics: First, interest dispute, not a power struggle over political economy; the second is greater than the right sense of awareness of the rules; third greater than the aggressive reaction, the basic with all their rights have been violated by a reaction to sexual behavior; fourth goal of the unlawful nature of legitimacy and co-exist (Jianrong Yu, 2008). These features do not involve core social values, and to vent their anger Group Incidents that without a clear purpose is not involved in core social values, which China's current mass incidents are totally positive function to play, especially in Group Events can make groups of local social problems, such as special interest groups dissatisfied with some unreasonable policies of local grass-roots government, bureaucracy, corruption and other grievances release, but also to avoid even greater. The social unrest and social conflict, and group events can also make managers aware of local existing social contradictions and social problems to be resolved as soon as possible.

In short, frequent outbreaks of mass incidents is the inevitable transformation of our society, it is an objective, we must face it, although the mass incidents have a negative function for society, but if the group events can reduce the intensity of conflict and resolve the deeper issue, it also can have a positive social function.

\subsection{Mass media coverage under the function of the incident and Countermeasures}

Mass incidents reported by the media play under the social "safety valve" function. In the "function of social conflict", a book, Coser first proposed the concept of social safety value. Lewis A. Coser regarded that the hostility and conflict is different, the conflict does not mean hostility, if hostility to vent through the appropriate channels, they will not lead to conflict, as excess steam through the boiler safety valve will not result in timely excluded Explode, thus contributing to the maintenance of social structure. Ancient and modern society both has this phenomenon; in fact it is a social security mechanism. Coser advocated such a mechanism should be institutionalized society and become the safety valve system. Accurate to say that the safety valve system, the structure is not destroyed under the condition that the hostile mood to release the need to maintain social integration, Coser' safety valve system that is necessary for any society, particularly necessary for the rigid society (L. A. Coser, 1989). To alleviate social contradictions, to prevent mass incidents, we must establish a social safety valve system. To establish a social safety valve system, we must build smooth social communication system. Smooth communication system allows people to fully and timely manner through various channels to express their interests and demands of institutionalized channels through vent grievances in a timely manner to prevent and reduce the accumulation of discontent; also enable the Government to listen to public opinions and social management Suggested, the correct grasp of public opinion and make decisions consistent with the scientific interests of the masses. This is equal to the installed between the government and the masses in a safe and effective, two-way interactive "safety valve" to resolve social conflicts, alleviate social conflicts. To this end, the media should act as such a "safety valve" so that different strata, different groups, 
different groups of people to express their views, put forward their own ideas, emotions and anger so that the community can be released. Recognize the function of media reports, China has reported incidents of mass needs to take the following two responses:

\subsection{To expanse the event space in the mass media coverage}

The analysis above shows that the media is not the case in the mass can not be, but impractical. In our current environment, eliminating the restrictions of mass media coverage of events were the key factors is to change the concept of government leadership. Games such as Chongqing taxi drivers strike On November 3, 2008 in Chongqing, a severe taxi strike made over 8'000 taxicabs disappear from the main roads in downtown. In the procession of handling the event, the Chongqing Municipal and Government haven't arrested the leader of the strike. Instead, they have tried best to understand the taxi drivers' behavior to cool down the conflicts. Finally the incident ended in peace. The third day of the incident event, Chongqing TV station broadcast a sudden temporary interruption of normal programming, live Bo Xilai, Party Secretary of taxi drivers and the public on behalf of the forum. Up to two and a half hours of live television, the first open national television media coverage of events is in response to mass precedent. The report, if not by Chongqing Party Secretary Bo approval, it is difficult to proceed smoothly. Although the current has been implemented in November 2007 the "PRC Emergency Response Law", the drafting process, managers removed the "unauthorized release of the news media shall not abuse emergency information", "unexpected events on the news media, local government related reports to management" and other provisions to strengthen the media release emergency information, autonomy, but there are still a few events in a group of local officials do everything possible to block message appears, or journalists, news media exert administrative pressure phenomenon, very few places or even beatings of journalists, reporting equipment damage or data scandal. Behavior of these errors, should be corrected, only to eliminate the limit media coverage of events for groups of factors, in order for the media coverage of events in the mass reported in the dare, to report.

In specific reports, in addition to the use of traditional mass media, we should also be adept at using the Internet, SMS and other new media to spread mass incidents involving the types of problems security crisis through the smooth and proper solution. This is because the network, mobile phone text messages in the mass events are often the platform for the dissemination of rumors, such as in the Weng'an incident, a female student on the cause of death and processing of information of various half-truths, with the modern means of communication to spread around, Makes the people come together know the truth, and finally led to mass incidents.

In addition, the expansion of space should also include changes in media coverage of mass incidents reported in the past, ideas of inertia, mass incidents reported on the attitude taken by fair, impartial and can not take sides, because favoritism or sympathy for any party, will only The situation worse, as the analysis above Weng'an incident, and fair coverage of the event was able to slow the intensity of conflict, helping to quell the incident, such as Hainan, "3 23 incident, On May 23, 2009 in Gancheng town, Dongfang City, Hainan Province, hundreds of villagers have attacked and burnt down the government of the town as well as the border police station. On May 25, a mass fight have also occurred in Gancheng Town." the third day, "Hainan Daily" published Oriental City disclosed the incident reported, more objective, both talked about the incident the whole process and fuse, also referred to the deep-seated reasons for the incident; only mentioned some of the local people a sense of law, but also that the "masses, especially Families of the victims of the police station handling the case is very efficient under" and "harm the local town government to the series of cases inadequate supervision", "deep contradiction between the two villages has always been" the cause of such incidents. The analysis is more objective, fair and let the people see that the Government is aware of where the problem it is (Chaojian Weng, 2009).

Finally, countries also need to put the event on the mass media under the rules or regulations to protect the right of the media coverage and an informed citizenry, and the ability of these rights had been violated when the State of relief, and for those who performed well on Play an active role in resolving conflicts in the media, the addition of mass incidents reported in Journalism Awards to show encouragement.

\subsection{Increase media coverage of social issues and the amount and degree of social contradictions}

In addition to the expansion in the mass media coverage of the event space, the need to increase media coverage of social issues and the amount and degree of social contradictions, it is because both the rights-based type of conflict, conflict or to vent their anger, which are already before the outbreak actually contains a large number of Social problems and social conflicts. Although these problems can be from the legal, institutional, etc. to solve, but if the disclosure through the media, you can become the focus of public attention, making the media event, causing the public and the government or stakeholders concern for social problems and social conflicts Solution 
to provide power. Such as CCTV Focus sometimes reflected in the problem has always been there, no law to rely on traditional approaches to resolve, however, once exposed, quickly resolve problems and conflicts. Function of the media spotlight, if we can care coverage that could potentially lead to mass social problems and social conflicts, it will lead to management's attention, to solve the problem in the bud early.

However, China's media coverage is currently limited mainly to promote a positive approach to social problems and social conflicts reported in both volume and the degree is still not enough. Graduate Institute of Journalism in 2005, according to Xinhua News Agency made a study on "trust in the media audience and satisfaction" of the sample survey, $81 \%$ of the audience that the media's "too little critical reporting, inadequate supervision by public opinion", 74.8\% audience that "the local government oversight is not enough". (Baowei Zheng, 2005) Critical reporting and supervision deficiencies, showing many of the local media, the media, especially social problems and social conflicts in front of omission, which is precisely the "mass incidents", one of the reasons frequently. Hebei Province in 2005, "Dingzhou incident", for example, in June 11 just before the village was attacked, "Dingzhou Daily" and "Hebei Youth Daily" for any relevant reports. Among them, "Dingzhou Daily" reports quoted local officials focus on the words to clarify meaning of Dingzhou power plant construction, the villagers heard the sound but not annihilation. "Hebei Youth Daily" reported in the focus of a basic fact-mainly because of land disputes in the amount of compensation is not to achieve consensus; But the report by the local propaganda department refers to as "repeated the baseless assertion, induction of the masses". In short, this stage is almost entirely in the village "Silence", ultimately allowing them to local government and the media, lack of basic trust. This led to 12 June at the scene, "Beijing News" interview, the villagers with "a strange and disdain in the eyes" staring at him, no one wants, and what he said, because "prior to a dial another wave of journalists, is to last just finished several Shihai", but although "we said over and over again, nothing more than taking was torn, up to now have not seen the word fart a big sign out to" (Lin Wu, 2006).

To this end, the media coverage and increase the critical public opinion, social problems and social conflicts will be open as soon as possible, not fear of the world without chaos, but to the social psychological guidance, to listen, to convey their opinions, and give full play to the advantage of the news media Effectively negotiated settlement related issues. Only in this way can the social problems and social conflicts behind the interests of vulnerable groups to carry out the demands, thereby reducing these vulnerable groups in the possibility of mass incidents, and ultimately reduce the occurrence of mass incidents.

\section{References}

Bon, G. L. (2004). Mobs-he research on the masses psychology. Beijing: Central Complication and Translation Press. 14.

Chan, Y. and Wang, J. (2009). The Rumours Control in Mass Emergency-Based on the Weng'an Event. Contemporary Communications, No. 3, 100-102.

Coser, L. A. (1989). The Function of Social Conflicts. Beijing: Huaxia Publishing House, 31-34.

Coser, L. A. (1960). Some Social Functions of Violence. Annals of the American Academy of Political and Social Scienc, 364 .

Guizhou Province. (2008). The Journalist Monthly. No. 8, 15-19.

Hu, J. T. (2008). The Speech on the Inspect of People's Daily. News Front, No. 7, 4-5.

Li, Q. (2005). Ding type Social Structure and 'Structural Strain. Research on Sociology, No. 2, 55-73.

Lin, R. Y. (1997). Economy and Society. Beijing: The Commercial Press, Volume 1. 239.

Liu, N. (2004). Resentment Explanation, Mobilization Structure and Reasonable Choices-Analyses on the Possibility of the Occurrence of Group Events in Urban Districts in China. Open Times, No. 4, 57-70.

Lu, X. Y. (2002). The Ten Classes in Contemporary China. Social Sciences Academic Press (China).

$\mathrm{Su}$, Y. T. (2008). Implementation of new law on information disclosure has encountered difficulties at its beginning. South weekly, July 10.

Sun, L. P. (2003). Fracture: Chinese Society Since 1990s. Beijing: Social Sciences Academic Press (China).

Ulrich Beck. (2004). Translated by Bowen He. Risk Society, Yilin Press, 15.

Wang, W. L.. The Spread of the Mass Emergency and Crises-Based on the ' 6.28 incident' in Weng'an.

Wei, X. W. and Gao, F. (2007).The Plight and Outlet of the handling of group events. Central Party School Journal, No.1. 
Weng, C. J. (2009). The Case and Principals in the Report of a Group Event. Chinese Journalists, No. 6, 67-68.

$\mathrm{Wu}$, L. (2006). Information Fatigue and the Spread Control. Journalism Quarterly, No. 3, 34-38.

Yu, G. R. (2008). The Venting Group Events in China and Governance difficulties. Contemporary World and Socialism, No. 1, 4-9.

Zhao, P. (2008). The alarm signals of 'typical group events. Outlook Weekly, No. 36.

Zheng, B. W. (2005). On the Construction of the Institutions of the Media's Supervision and Standard Management System. News Journalists, No. 10.

Zheng, W. D. (2006). Petition System and Expressions of the Farmers Interests. The Journals of Shanxi normal University, No. 5, 10-14.

Zhu, L. (2006). Pain in Changes-Analyses on the Anomie of the Society in Transition. Social Sciences Academic Press (China), 74.

Zhu, L. (2009). Analyses on Chinese Social Risks-The Nature of Group Events in Social Conflicts. XueHai, The 1 st issue, 69-78.

\section{Appendix}

\begin{tabular}{|c|c|c|c|}
\hline & Latency period report & $\begin{array}{l}\text { Fermentation period } \\
\text { report }\end{array}$ & First formal report \\
\hline $\begin{array}{l}\text { Dingzhou Event } \\
\text { (on June 11st, } \\
\text { 2005) }\end{array}$ & $\begin{array}{l}\text { Few local media reports of the } \\
\text { event related to land-levying } \\
\text { dispute. Only two pieces can be } \\
\text { found so far, one from "Hebei } \\
\text { Youth Daily" in July 2004, the } \\
\text { other from "Dingzhou Daily" in } \\
\text { November 17th, 2004. }\end{array}$ & $\begin{array}{l}\text { No reports from the } \\
\text { first attack on April } \\
\text { 20th, } 2005 \text { to the } \\
\text { second attack on June } \\
\text { 11st, } 2005 .\end{array}$ & $\begin{array}{l}\text { Reports entitled "Several } \\
\text { hundred people with hunting } \\
\text { rifles and knives have } \\
\text { attacked the villagers in } \\
\text { Dingzhou City and led to } 6 \\
\text { deaths" from "The Beijing } \\
\text { News". }\end{array}$ \\
\hline $\begin{array}{l}\text { Weng'an Event } \\
\text { (on June 28th, } \\
\text { 2008) }\end{array}$ & $\begin{array}{l}\text { No reports concerning the details } \\
\text { such as relocation of the local } \\
\text { reservoir emigrants, cites' } \\
\text { transformation and relocation, the } \\
\text { ore ownership dispute on coal mine } \\
\text { or phosphorite, and state-owned } \\
\text { enterprises restructuring. }\end{array}$ & $\begin{array}{l}\text { No information } \\
\text { collection, no } \\
\text { warning and } \\
\text { study, judgments of } \\
\text { the information, no } \\
\text { information reported } \\
\text { and published }\end{array}$ & $\begin{array}{l}\text { Report entitled "The } \\
\text { violence incident happened } \\
\text { in Wen'an City, Guizhou } \\
\text { Province" from the } \\
\text { XinhuaNet. }\end{array}$ \\
\hline $\begin{array}{l}\text { MengLian Event } \\
\text { (July 7, 2008) }\end{array}$ & $\begin{array}{l}\text { Rubber farmers had long-term } \\
\text { interest conflicts with rubber } \\
\text { company, media reported no } \\
\text { detailed. }\end{array}$ & $\begin{array}{l}\text { From July } 11,2008 \\
\text { the transfer of the } \\
\text { municipal public } \\
\text { security bureau } \\
\text { police to rally in } \\
\text { MengLian to July } 19 \\
\text { the event broke out, } \\
\text { no media reported. }\end{array}$ & $\begin{array}{l}\text { On July 20, 2008, } \\
\text { XinhuaNet reported with the } \\
\text { title Violence occured in } \\
\text { MengLian, Yunnan, good } \\
\text { rehabilitative works and } \\
\text { mass work are required by } \\
\text { the provincial government. }\end{array}$ \\
\hline $\begin{array}{l}\text { Shishou Event } \\
\text { (June 19, 2009) }\end{array}$ & $\begin{array}{c}\text { On the local drug problems, only } \\
\text { had the news as Two drug dens had } \\
\text { been destroyed in Shishou reported } \\
\text { by Jianghan Business News on } \\
\text { November } 14,2008 \text { and some } \\
\text { Sporadic reports. }\end{array}$ & $\begin{array}{l}\text { From June } 17 \text { to } 19, \\
\text { 2009, no media } \\
\text { reported. }\end{array}$ & $\begin{array}{l}\text { On June } 19,2009, \text { the } \\
\text { government website of } \\
\text { Shishou reported with the } \\
\text { title Abnormal deaths occur } \\
\text { together in our city. }\end{array}$ \\
\hline
\end{tabular}

